\title{
Intraoperative options for treating atrial fibrillation associated with mitral valve disease
}

James L. Cox, MD

Received for publication April 10, 2001; accepted for publication April 16, 2001.

Address for reprints: James L. Cox, MD, The World Heart Foundation, 1828 L St NW, Suite 1100, Washington, DC 20036.

J Thorac Cardiovasc Surg 2003;125:S24-7 Originally published in J Thorac Cardiovasc Surg 2001;122:212-5.

Copyright $\left({ }^{\circ} 2003\right.$ by The American Association for Thoracic Surgery

$0022-5223 / 2003 \$ 30.00+0$

doi: $10.1067 / \mathrm{mtc} .2003 .215$

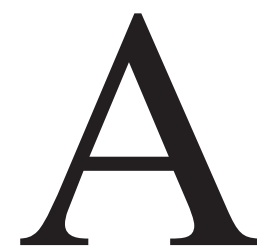

trial fibrillation is present in approximately $50 \%$ of all patients undergoing surgery for the treatment of mitral valve disease. ${ }^{1-3}$ For more than 40 years, cardiac surgeons have been forced to ignore this associated atrial fibrillation at the time of open mitral valve surgery because there has been no effective way to treat it. After the success of the maze procedure in treating atrial fibrillation, ${ }^{4-6}$ several surgeons began to add the maze procedure as an adjunct to mitral valve surgery to treat both problems. ${ }^{7-9}$ When properly performed, the results with this combined approach have been excellent, with no increase in perioperative morbidity or operative mortality and with documented long-term advantages over simply leaving patients in atrial fibrillation. ${ }^{8} 9$ Despite these results, adding the maze procedure to mitral valve surgery significantly prolongs and complicates the operation; therefore, most surgeons have understandably been reluctant to perform the combined procedure.

During the past 2 to 3 years, cardiologists have become extremely aggressive in their efforts to treat atrial fibrillation by modifications of the percutaneous radiofrequency catheters that have been so successful in treating other types of arrhythmias, especially the Wolff-Parkinson-White syndrome. ${ }^{10-13}$ It was only a matter of time until some surgeons used these same percutaneous endocardial catheters to treat atrial fibrillation intraoperatively when performing mitral valve surgery. This new surgical intervention was quickly recognized by medical device companies as a new market and, as a result, new radiofrequency devices have been adapted specifically for intraoperative use.

In this issue of the Journal [J Thorac Cardiovasc Surg 2001;122:249-56], the group from Maastricht, The Netherlands, describes the use of intraoperative radiofrequency catheters to ablate atrial fibrillation in patients who required surgery primarily for mitral valve disease. This study is particularly important because it comes from perhaps the premier electrophysiology group in the world, especially in the area of atrial fibrillation. Clinical electrophysiology was born in the laboratory of Professor Dirk Durrer of Amsterdam and led to his becoming the first to perform an intraoperative electrophysiologic map of the human heart in 1957. In 1967, Dr Durrer's brilliant protégé, Professor Hein J. J. Wellens, one of the authors of this article, described the technique of programmed electrical stimulation that provided a method for reproducibly inducing and terminating reentrant arrhythmias. This landmark achievement made possible the systematic characterization of most clinical arrhythmias and has remained largely unchanged since that time. Thus, it behooves us all to listen when this group speaks of electrophysiology matters!

The authors describe their experience with the use of intraoperative radiofrequency catheters to create linear lesions in both atria in an effort to ablate atrial fibrillation associated with other surgical heart disease in 122 patients, 108 of whom had associated mitral valve surgery. The pattern of lesions placed in the atria was described as "a modification of the maze III procedure." Actuarial freedom from atrial flutter or atrial fibrillation at 39 months was $78.5 \% \pm 5.1 \%$.

These results are consistent with those obtained by Melo's group in Portugal, ${ }^{14}$ Mohr's group in Leipzig, Germany, ${ }^{15}$ and Alfieri's group in Italy, ${ }^{16}$ all of whom also use radiofrequency energy to create the lesions in the atria. Similar results have also been attained by Stephan Schuler in Dresden, Germany, ${ }^{17}$ using microwave energy 
to create the atrial lesions. However, these studies raise an important question. Why are $20 \%$ to $30 \%$ of the patients not cured of their atrial fibrillation? Assuming that an $80 \%$ cure rate is not acceptable to most cardiac surgeons, we are obligated to answer that question.

During the past several years, at least two major observations regarding atrial fibrillation have had a direct impact on these new intraoperative techniques to treat atrial fibrillation associated with mitral valve disease. The first is that the maze procedure, when properly performed, cures atrial fibrillation in nearly $100 \%$ of patients with or without mitral valve disease. ${ }^{4-6}$ The second is that the majority of paroxysmal (intermittent) atrial fibrillation originates within the orifices of one or more of the pulmonary veins. ${ }^{18}$ Thus, to my knowledge, all of the techniques now being used to treat atrial fibrillation during mitral valve surgery incorporate some combination of the linear lesions of the maze procedure with isolation of one or more of the pulmonary vein orifices. Unfortunately, the scientific basis for these various approaches is somewhat less than completely sound.

A cardinal rule of scientific experimentation is that all variables in an experiment must be controlled except the one variable that is being studied. Thus, when attempting to modify a successful operative procedure, one should avoid introducing more than one variable if the final results of the modification are to be subject to scientific interpretation. Unfortunately, these recent attempts to ablate atrial fibrillation at the time of mitral valve surgery have violated that principle, because multiple variables have been introduced simultaneously, thereby precluding our ability to identify the reason for the $20 \%$ failure rate. For example, the following combinations of variables are currently in the mix of intraoperative approaches to the treatment of atrial fibrillation during mitral valve surgery.

1. Different energy sources to create atrial lesions: These include radiofrequency energy, microwave energy, laser energy cryosurgery, and the cut-and-sew technique.

2. Different locations of the atrial lesions: These include "left-sided mazes," "right-sided mazes," pulmonary vein encirclement only, and the connection of various pulmonary vein orifices in various combinations with or without a contiguous lesion down to the mitral valve anulus, ignoring the importance of the coronary sinus in postoperative atrial flutter and fibrillation.

\section{Energy Source}

The basis of all arrhythmia surgery since Dr Sealy's first operation for the Wolff-Parkinson-White syndrome in $1968^{19}$ is that the fibrocytes that make up scar tissue will not conduct electricity. Indeed, fibrocytes may well be the most effective insulators against electrical conduction in all of nature, since a single cell layer of fibrocytes will block electrical conduction in the heart permanently. For a line of complete conduction block to be created, however, a lesion placed in the atrial wall must be transmural or else electrical activity can traverse the line of the lesion. ${ }^{20}$ For example, if a linear radiofrequency lesion is placed on the endocardial side of the atrium and is not transmural, electrical activity can traverse the line of the lesion on its epicardial side. Conversely, if a linear lesion is placed on the epicardial side of the atrium and is not transmural, electrical activity can traverse the line of the lesion on its endocardial side.

When the maze procedure was originally developed, we chose to use the cut-and-sew technique exclusively for one simple reason: We could be absolutely certain that each and every atrial lesion was transmural because we could see that it was. We then placed a cryolesion at any site where there might be microscopic connections remaining that could not be seen and that might allow electrical conduction to "bridge" the otherwise transmural atrial lesion. These sites included the ends of two right atriotomies that terminated at the tricuspid valve anulus, one left atriotomy that terminated at the mitral valve anulus, and the coronary sinus that itself bridges one of the posterior left atriotomies. By using this technique exclusively, we could be certain that if the operation ultimately failed, it would do so because it was based on a faulty concept, not because it had been performed incorrectly or incompletely.

When we had to make the first modification of the maze procedure (from the maze I to the maze II procedure), ${ }^{21,22}$ the only variable that was introduced was a slight change in the precise pattern of the atrial lesions. The basic cut-andsew technique was left unchanged. Again, when we made the second modification (from the maze II to the maze III procedure), ${ }^{21,22}$ we still were careful to introduce only one variable, a change in the pattern of the atriotomies, with the modification. As a result, the efficacy of the maze procedure in curing atrial fibrillation remained unchanged from the maze I to the maze II to the maze III, but the undesirable side-effects of the first two procedures were eliminated by these modifications.

The major problem with using radiofrequency, microwave, or laser energy to treat atrial fibrillation is that there is no way to document with certainty that a lesion is transmural at the time it is created. Studies have been performed to relate the depth of a lesion to the energy expended, time of application, and temperature of the probe tip, ${ }^{23-25}$ but the fact remains that there is simply no real-time method of being certain that a given lesion is transmural using these energy sources.

What, then, are the alternatives to creating the lesions with the old cut-and-sew technique that allow for real-time documentation of the transmurality of the linear lesions? We now use cryosurgery for the creation of these linear lesions, ${ }^{9}$ rather than the cut-and-sew technique, because the surgeon simply has to look at the cryolesion to see when it 
has become transmural. Once the ice ball has become transmural, the cryoprobe is held in place for 120 seconds and then defrosted. The certainty of permanent transmurality with this method is based on scientific and clinical studies dating back over 25 years to when cryosurgery was first used intraoperatively to treat cardiac arrhythmias. ${ }^{26-28}$ In fact, we now perform the entire maze procedure using linear cryoprobes, rather than the cut-and-sew technique, whether or not it is performed in combination with mitral valve surgery.

\section{Pattern of Atrial Lesions}

The recent demonstration by Haissaguerre and associates ${ }^{18}$ that the majority of atrial fibrillation originates within the pulmonary veins was at once a magnificent revelation for basic electrophysiologists and a treacherous trap for unsuspecting interventional electrophysiologists and arrhythmia surgeons. This important contribution to the understanding of atrial fibrillation does not represent the holy grail for treatment purposes, but rather it is the remaining piece of the previously incomplete puzzle of atrial fibrillation. It fits with the other pieces in the following manner.

Under normal circumstances, the atria are activated by the sinus node, remain in sinus rhythm, and are extremely resistant to the development of atrial fibrillation, as evidenced by the fact that less than $2 \%$ of the general population is in atrial fibrillation. ${ }^{29}$ Because there is a transition zone between the endothelium of the pulmonary veins and the endocardium of the left atrium, this is the proper milieu for the development of MICRO-reentry circuits that can lead to premature atrial beats. These premature atrial beats, in turn, can stimulate the atria in such a manner that MACRO-reentrant circuits are set up in the atria that become self-perpetuating. This is atrial fibrillation. ${ }^{30}$ In other words, the atrial fibrillation is initiated by micro-reentrant circuits within the pulmonary veins and is sustained by macroreentrant circuits in the atrial myocardium itself.

Usually, the atria retain their natural tendency to remain in a normal rhythm, so they will eventually spontaneously revert to a normal sinus rhythm. Later, the micro-reentry circuits in the pulmonary veins reinduce atrial fibrillation, and we recognize the clinical picture of paroxysmal (intermittent) atrial fibrillation. This type of atrial fibrillation can be cured by one of the following techniques:

1. Identifying the culprit pulmonary vein and ablating the micro-reentrant circuit within its orifice

This is the basis for the percutaneous endocardial catheter mapping followed by map-guided radiofrequency ablation within a single pulmonary vein orifice that is now performed by interventional electrophysiologists.

2. Identifying the culprit pulmonary vein and isolating its orifice from the remainder of the atrial myocardium
This also involves catheter mapping by interventional electrophysiologists but is followed by attempts at placing circumferential rings of block around the orifice of the culprit pulmonary vein using either radiofrequency, cryothermia, ultrasound, microwave, or laser energy sources.

3. Isolating the orifices of all four pulmonary veins from the remainder of the atrial myocardium

This is the most logical way for surgeons to treat this type of atrial fibrillation during mitral valve surgery because there is currently no way of identifying the culprit pulmonary vein intraoperatively.

Unfortunately, as the atrium begins to fibrillate more and more, it undergoes a process that has been described as "atrial remodeling" by Professor Maurits Allessie, ${ }^{31}$ one of Professor Wellens' brilliant colleagues in Maastricht. Allessie describes the results of this electrophysiologic (and perhaps anatomic) remodeling as "atrial fibrillation begets atrial fibrillation." In other words, the more the atrium fibrillates, the more it is inclined to fibrillate. Finally, in most patients, the paroxysmal atrial fibrillation evolves into chronic (continuous) atrial fibrillation because of this process of atrial remodeling.

From the treatment standpoint, it is critical to understand that once this has occurred, the pulmonary veins, and the latent or active micro-reentrant circuits that they may harbor, become irrelevant to the maintenance of the atrial fibrillation. In other words, not even complete isolation of all four pulmonary veins will ablate the atrial fibrillation at this point, and certainly anything less than their complete isolation cannot be expected to be effective. Indeed, the only known nonpharmacologic way to stop the atrial fibrillation at this point is to render the atria incapable of harboring the macro-reentrant circuits that are the basis of atrial fibrillation once it is established. This is what the maze procedure does. Unfortunately, no other pattern of atrial lesions has yet been described to accomplish this goal.

In summary, the attempts at ablating atrial fibrillation during mitral valve surgery using multiple energy sources that are easy to handle and quick to apply is to be strongly encouraged. However, surgeons should make every effort to assure that the lesions they create are transmural in every instance, or else the operation is doomed to a high rate of failure.$^{20}$ Furthermore, until a less complex pattern of atrial lesions has been shown to be as effective as the maze procedure, I believe that the pattern of lesions applied during surgery should conform exactly, or nearly so, to the pattern of the maze procedure. With minor modifications, the maze procedure can now be performed with the use of linear cryoprobes to assure transmurality without substantially increasing either the complexity or the duration of mitral valve surgery and with the expectation that $99 \%$ of the atrial fibrillation associated with the mitral valve disease 
will be cured. That should be the goal of any other energy source and of any other pattern of atrial lesions.

\section{References}

1. Chua YL, Schaff JV, Orszulak TA, Morris JJ. Outcome of mitral valve repair in patients with preoperative atrial fibrillation: Should the maze procedure be combined with mitral valvuloplasty? J Thorac Cardiovasc Surg. 1994;107:408-15.

2. Obadia JF, el Farra M, Bastien OH, Lievre M, Martelloni Y, Chassignolle JF. Outcome of atrial fibrillation after mitral valve repair. J Thorac Cardiovasc Surg. 1997;114:179-85.

3. Jessurun ER, van Hemel NM, Kelder JC, Elbers S, de la Rivière AB, Defauw JJ, Ernst JM. Mitral valve surgery and atrial fibrillation: Is atrial fibrillation surgery also needed? Eur J Cardiothorac Surg. 2000;17:530-7.

4. Cox JL, Boineau JP, Schuessler RB, Ferguson TB Jr, Cain ME, Lindsay BD, et al. Successful surgical treatment of atrial fibrillation. JAMA. 1991;266:1976-80.

5. Cox JL, Boineau JP, Schuessler RB, Kater KM, Lappas DG. Five-year experience with the maze procedure for atrial fibrillation. Ann Thorac Surg. 1994;56:814-24.

6. Cox JL, Schuessler RB, Lappas DG, Boineau JP. An 81/2 year clinical experience with surgery for atrial fibrillation. Ann Thorac Surg. 1996; 224:267-75

7. Kosakai Y, Kawaguchi AT, Iskobe F, Sasako Y, Nakano K, Eishi K, et al. Modified maze procedure for patients with atrial fibrillation undergoing simultaneous open heart surgery. Circulation. 1995; 92(Suppl):II-359-64.

8. Handa N, Schaff HV, Morris JJ, Anderson BJ, Kopecky SL, EnriquezSarano M. Outcome of valve repair and the Cox maze procedure for mitral regurgitation and associated atrial fibrillation. J Thorac Cardiovasc Surg. 1999;118:628-35.

9. Cox JL, Ad N, Palazzo T, Fitzpatrick S, Suyderhoud JP, DeGroot KW, et al. The maze-III procedure combined with valve surgery. Semin Thorac Cardiovasc Surg. 2000;12:53-5.

10. Pelosi F Jr, Morady F. Evaluation and management of atrial fibrillation. Med Clin North Am. 2001;85:225-44.

11. Chen SA, Tai CT, Hsieh MH, Tsai CF, Ding YA, Chang MS. Radiofrequency catheter ablation of atrial fibrillation initiated by spontaneous ectopic beats. Eurospace. 2000;2:99-105.

12. Luderitz B. Catheter ablation for atrial fibrillation and atrial flutter: from D.C. shocks to radiofrequency current. J Interv Card Electrophysiol. 2000;4:441.

13. Kumagai K, Tojo H, Yasuda T, Noguchi M, Matsumoto N, Nakashima $\mathrm{H}$, et al. Treatment of mixed atrial fibrillation and typical atrial flutter by hybrid catheter ablation. Pacing Clin Electrophysiol. 2000;23:1839-42.

14. Melo J, Adragao P, Neves J, Ferreira M, Timoteo A, Santiago T, et al. Endocardial and epicardial radiofrequency ablation in the treatment of atrial fibrillation with a new intra-operative device. Eur J Cardiothorac Surg. 2000;18:182-6.

15. Walther T, Falk V, Walther C, Krauss B, Hindricks G, Kottkamp H, et al. Combined stentless mitral valve implantation and radiofrequency ablation. Ann Thorac Surg. 2000;70:1080-2.

16. Benussi S, Pappone C, Nascimbene S, Oreto G, Caldarola A, Stefano $\mathrm{PL}$, et al. A simple way to treat chronic atrial fibrillation during mitral valve surgery: the epicardial radiofrequency approach. Eur J Cardiothorac Surg. 2000;17:524-9.
17. Knaut M, Spitzer SG, Karolyi L, Ebert HH, Richter P, Tugtekin SM, et al. Intraoperative microwave ablation for curative treatment of atrial fibrillation in open heart surgery-the MICRO-STAF and MICROPASS pilot trial. MICRO wave application in surgical treatment of atrial fibrillation. MICRO wave application for the treatment of atrial fibrillation in bypass surgery. Thorac Cardiovasc Surg. 1999; 47(Suppl):379-84.

18. Haissaguerre M, Jais P, Shah DC, Takahashi A, Hocini M, Quiniou G, et al. Spontaneous initiation of atrial fibrillation by ectopic beats originating in the pulmonary veins. N Engl J Med. 1998;339:659-66.

19. Cobb FR, Blumenschein SD, Sealy WC, Boineau JP, Wagner GS, Wallace AG. Successful surgical interruption of the bundle of Kent in a patient with Wolff-Parkinson-White syndrome. Circulation. 1968; 38:1018-29.

20. Thomas SP, Wallace EM, Ross DL. The effect of a residual isthmus of surviving tissue on conduction after linear ablation in atrial myocardium. J Intervent Card Electrophysiol. 2000;4:273-81.

21. Cox JL, Boineau JP, Schuessler RB, Lappas DG. Modification of the maze procedure for atrial flutter and atrial fibrillation: rationale and surgical results. J Thorac Cardiovasc Surg. 1995;110:473-84.

22. Cox JL, Jaquiss RD, Schuessler RB, Boineau JP. Modification of the maze procedure for atrial flutter and atrial fibrillation. II. Surgical technique of the maze III procedure. J Thorac Cardiovasc Surg. 1995; 110:485-95.

23. Erdogan A, Grumbrecht S, Carlsson J, Roederich H, Schulte B, Sperzel J, et al. Homogeneity and diameter of linear lesions induced with multipolar ablation catheters: in vitro and in vivo comparison of pulsed versus continuous radiofrequency energy delivery. $J$ Interv Card Electrophysiol. 2000;4:655-61.

24. Ndrepepa G, Schneider MA, Vallaint A, Zrenner B, Karch MR, Schreieck J, et al. Acute electrophysiologic effects and antifibrillatory actions of the long linear lesions in the right atrium in a sheep model. J Interv Card Electrophysiol. 2000;4:529-36.

25. Taylor GW, Walcott GP, Hall JA, Bishop S, Kay GN, Ideker RE. High-resolution mapping and histologic examination of long radiofrequency lesions in canine atria. J Cardiovasc Electrophysiol. 1999;10: 1467-77.

26. Gallagher JJ, Sealy WC, Anderson RW, Kasell J, Millar R, Campbell $\mathrm{RW}$, et al. Cryosurgical ablation of accessory atrioventricular connections: a method for correction of the pre-excitation syndrome. Circulation. 1977;55:471-9.

27. Holman WL, Ikeshita M, Ungerleider RM, Smith PK, Ideker RE, Cox JL. Cryosurgery for cardiac arrhythmias: acute and chronic effects on coronary arteries. Am J Cardiol. 1983;51:149-55.

28. Holman WL, Ikeshita M, Douglas JM, Smith PK, Cox JL. Cardiac cryosurgery: effects of myocardial temperature on cryolesion size. Surgery. 1983;93:268.

29. Kulbertus HE, Olsson SB, Schlepper M, editors. Atrial fibrillation: Proceedings of a symposium held in Kiruna, Sweden, June 24-27, 1981. Arranged jointly by the University of Göteborg, Sweden, the University of Liège, Belgium, and the Max-Planck Institute, Bad Nauheim, Germany. Sponsored by AB Hässle, subsidiary within the Astra Group, Sweden. Published in 1982.

30. Cox JL, Canavan TE, Schuessler RB, Cain ME, Lindsay BD, Stone C, et al. The surgical treatment of atrial fibrillation. II. Intraoperative electrophysiologic mapping and description of the electrophysiologic basis of atrial flutter and atrial fibrillation. J Thorac Cardiovasc Surg. 1991;101:406-26.

31. Allessie MA. Atrial electrophysiologic remodeling: Another vicious circle? J Cardiovasc Electrophysiol. 1998;9:1378-93. 